\title{
Ideas and Innovations
}

\section{Harvesting split thickness costal cartilage graft}

\author{
Sunil Gaba, Richa Gupta1, Bharat Mishra, Daisy Sahni' \\ Departments of Plastic and Reconstructive Surgery and ${ }^{1}$ Anatomy, Postgraduate Institute of Medical Education and Research, \\ Chandigarh, India
}

Address for correspondence: Dr. Sunil Gaba, Department of Plastic and Reconstructive Surgery, Postgraduate Institute of Medical Education and Research, Sector 12, Chandigarh - 160 012, India. E-mail: drsgaba@gmail.com

\section{ABSTRACT}

Aim: There are few complications associated with harvesting of full thickness coastal cartilage grafts i.e., pneumothorax $(0.9 \%)$, contour deformities and prolonged post-operative pain. To address these issues, authors devised special scalpel to harvest split-thickness costal cartilage grafts. Materials and Methods: Standard inframammary incision was used for harvesting rib. Incision was made directly over the desired rib. Specially designed scalpel was used to cut through the rib cartilage to the half of the thickness. The study was conducted in two parts - cadaveric and clinical. Results: There was significantly less pain and no pneumothorax in the patients in whom the split thickness graft was harvested. Wounds healed without any complication. Discussion: Thus, newly devised angulated scalpel used in the current study, showed the potential to supply the reconstructive surgeon with split thickness rib graft without risk of complications such as pneumothorax or warping contour deformities and post-operative pain.

\section{KEY WORDS}

Graft; pneumothorax; rib; scalpel; split

\section{INTRODUCTION}

utologous tissue is always preferred because the use of alloplastic material increases the rate of infection and/or extrusion. ${ }^{[1-6]}$ The rib provides the most abundant source of cartilage for graft fabrication and is the material of choice when reliable structural support is needed. ${ }^{[7]}$ Costal cartilage grafts are commonly used for the reconstruction of calvarium, mandible, orbital floor and nose. Commonly used method is to harvest full thickness rib graft and then split into desired thickness, and remaining cartilage is discarded. Several complications

\begin{tabular}{|l|l|}
\hline \multicolumn{2}{|c|}{ Access this article online } \\
\hline Quick Response Code: & Website: \\
\hline & www.ijps.org \\
\cline { 2 - 2 } & DOI: \\
\hline
\end{tabular}

are associated with harvesting of full thickness coastal cartilage grafts i.e., pneumothorax $(0.9 \%)$, contour deformities and prolonged post-operative pain. To address these issues, we have been harvesting split thickness costal cartilage grafts.

\section{IDEAS AND INNOVATION}

The cadaveric study was conducted as a trial to test the feasibility, maneuverability and subsequent modifications before actual clinical use. This device was

This is an open access article distributed under the terms of the Creative Commons Attribution-NonCommercial-ShareAlike 3.0 License, which allows others to remix, tweak, and build upon the work non-commercially, as long as the author is credited and the new creations are licensed under the identical terms.

For reprints contact: reprints@medknow.com

How to cite this article: Gaba S, Gupta R, Mishra B, Sahni D. Harvesting split thickness costal cartilage graft. Indian J Plast Surg 2017;50:79-81. 
used on five cadavers ranging in age from 47 to 70 years [Figures 1 and 2]. Through cadaveric study, the height of handle of the device and its angulation was determined so as to provide space to soft tissue while inserting device in intercostals space. We had earlier designed motorized rib cutter prototype, but it had certain practical issues like high cost as piezoelectric crystals were used to make the device motorized; difficulty in achieving $100 \%$ sterility of device due to attached battery and length of blade due to which it could not be inserted in a small incision.

Hence, then authors redesigned normal scalpel by reducing the length of the blade ( $x$ limb) and increasing the height of the handle (y limb) so as to provide space to soft tissue [Figure 1]. It was designed so that a 10 or 23 number disposable blade could be fixed to it. This device is an angulated non-motorized rib cutter device. It has been angulated in two places, first one, about $110^{\circ}$, where the blade assembly was attached and second one, about $70^{\circ}$, where it is to be held while taking the graft.

\section{MATERIALS AND METHODS}

The device was used in five patients of various age groups for cartilage graft for dorsal augmentation, spreader grafts and columellar strut in rhinoplasty. The cause of saddling in these patients was facial trauma and submucous resection of the nasal septum.

The standard inframammary incision was used for harvesting rib. The incision was made directly over the desired rib V or VI. Skin, superficial and deep thoracic fascia was incised, and perichondrium was incised along the axis of the rib. Then exposed rib was marked, and initial marking cuts were made with the help of side cutting burr up to desired width [Figure 3]. In all the patients, the specially designed device was used to cut through the rib cartilage to the half of the thickness so as to harvest rib graft. To and fro movements were made to harvest the split thickness graft [Figure 4]. Hemostasis was achieved, and Incision was closed in layers. Limitation of using split thickness cartilage graft could be the warping. However, for dorsal augmentation, diced cartilage wrapped in rectus fascia was used. Hence, there was no question of warping in these cases.

\section{RESULTS}

Preoperatively, all the patients were found to have variable degrees of broadening of the nasal dorsum, shortening

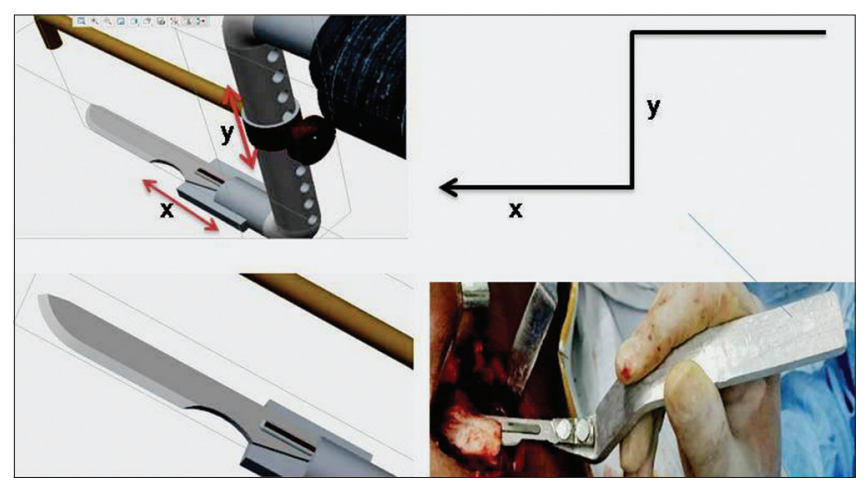

Figure 1: Non-motorized rib cutter device - The handle $(x)$ was made by cutting and bending an aluminium sheet. It was designed so that a 10 or 22 number disposable blade could be fixed to it. It has been angulated in two places, first one $(y)$, about $110^{\circ}$, where the blade is attached and second one, about $70^{\circ}$, where it is to be held while taking the graft

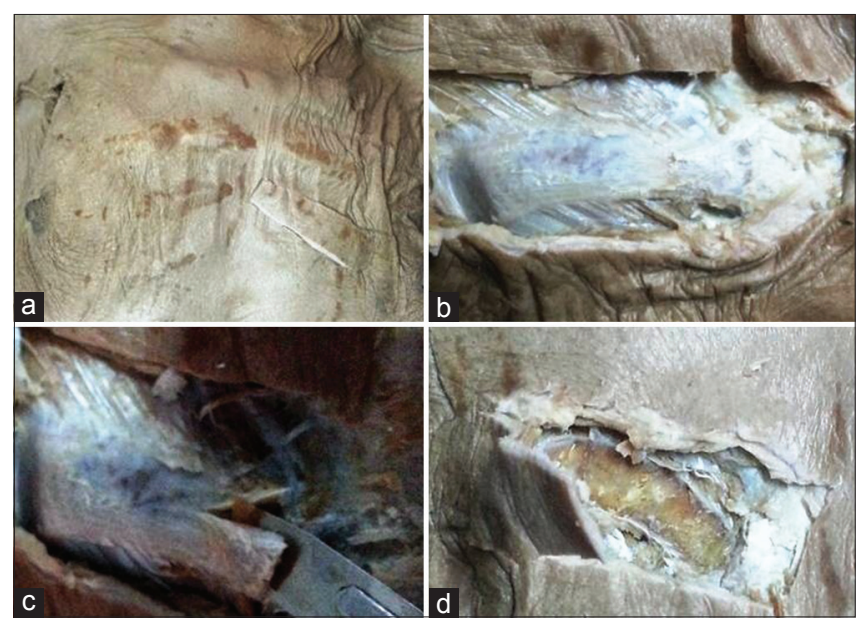

Figure 2: (a) Cadaver thorax. (b) Exposure of the rib. (c) Split rib harvested using the specially designed scalpel. (d) Post split rib harvesting showing no damage to rest of rib and underlying pleura

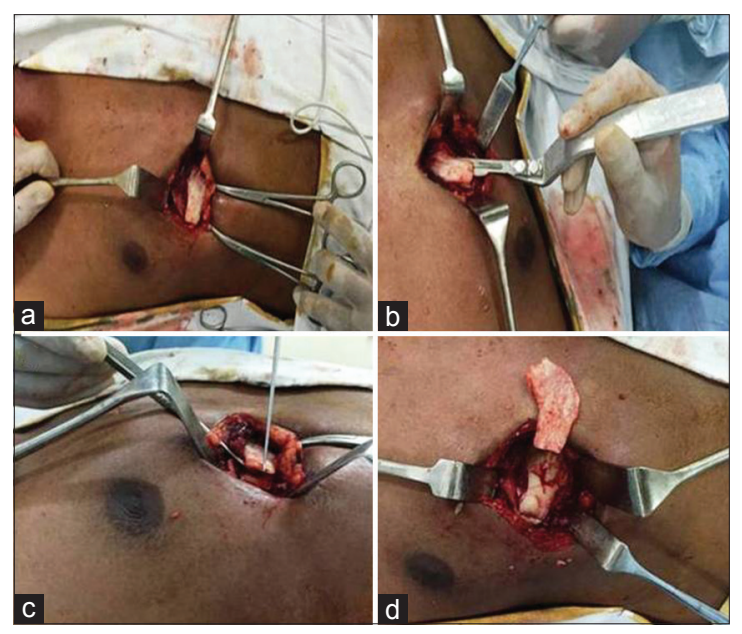

Figure 3: (a) Exposure of the rib to be harvested through infra mammary incision. (b-c) Split rib harvested using the specially designed scalpel. (d) Harvested split rib and donor rib showing no breach in continuity and safety of pleura

of the columella and tip deformity. Postoperatively, all the patients reported satisfactory aesthetic results. None 


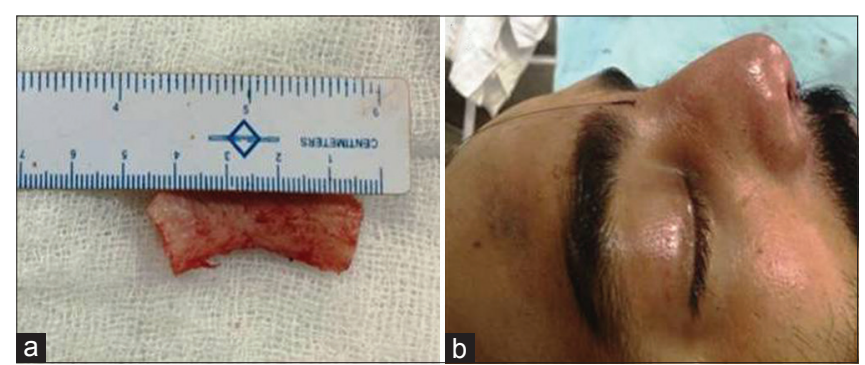

Figure 4: (a) Harvested split thickness cartilage (b) diced cartilage wrapped in rectus fascia for dorsal augmentation

of the grafts was extruded. Wounds healed without reported infections. This was followed by improvement of the aesthetic deformity was noted in all patients especially in all the patients. Considering the donor site morbidity, none of the cases had wound dehiscence or pneumothorax. Post-operative pain was compared with other patients $(n=5)$ in whom full thickness of cartilage was harvested using visual analogue score (VAS). ${ }^{[1-10]}$ This was recorded on post-operative day 1, day 3 and day 7 . Mean VAS in this group was 3.7 (vs. 6.2), 3.2 (vs. 5.8) and 2.4 (vs. 4.9) on post-operative day 1 , day 3 and day 7 , respectively. There was significantly less pain in the patients in whom the split thickness graft was harvested.

\section{DISCUSSION}

The costal cartilage grafts have versatile application in reconstructive procedures. ${ }^{[8]}$ However, most of the times, we take out whole rib, we use only some part and rest is discarded..$^{[9-11]}$ The normal procedure of harvesting costal cartilage graft is skin incision along the anterior surface of the rib and circumferential dissection from both surfaces by curved and Doyen retractor. The bone is then separated from the chondral junction and cut posteriorly with bone cutting forceps. During harvesting, continuous palpation of the underlying rib is required to avoid pleural injury. The advantages of this innovation are no chances of causing pneumothorax and reduced post-operative chest pain. Reduced chest pain can be attributed to the maintained rib continuity. The post-operative threat of pneumothorax is the major rib graft donor site morbidities. The former was reduced in the current study by use of a specially devised angulated scalpel in which disposable number 10 or 23 blade is fixed. It was used to cut through the rib cartilage to the half of the thickness. By use of this devise, post-operative complication threat of pneumothorax was easily avoided and even post-operative wound recovery was remarkable. Thus, newly devised angulated scalpel used in the current study showed the potential to supply the reconstructive surgeon with split thickness rib graft. Split thickness rib grafting reduces the post-operative pain and other complications are less because of maintenance of rib continuity. However, the limitation of this device is when estimated graft volume is high and also its reproducibility has not yet been tested.

\section{CONCLUSION}

The newly devised angulated scalpel used in the current study has the potential to supply sufficient split thickness rib graft with decrease risk of complications such as pneumothorax or contour deformities and reduced postoperative pain.

\section{Financial support and sponsorship \\ Nil.}

\section{Conflicts of interest}

There are no conflicts of interest.

\section{REFERENCES}

1. Ahn J, Honrado C, Horn C. Combined silicone and cartilage implants: Augmentation rhinoplasty in Asian patients. Arch Facial Plast Surg 2004;6:120-3.

2. Conrad K, Gillman G. A 6-year experience with the use of expanded polytetrafluoroethylene in rhinoplasty. Plast Reconstr Surg 1998;101:1675-83.

3. Deva AK, Merten S, Chang L. Silicone in nasal augmentation rhinoplasty: A decade of clinical experience. Plast Reconstr Surg 1998;102:1230-7.

4. Fanous N, Samaha M, Yoskovitch A. Dacron implants in rhinoplasty: A review of 136 cases of tip and dorsum implants. Arch Facial Plast Surg 2002;4:149-56.

5. Hobar PC, Pantaloni M, Byrd HS. Porous hydroxyapatite granules for alloplastic enhancement of the facial region. Clin Plast Surg 2000;27:557-69.

6. Jackson IT, Yavuzer R, Silverstein P. Alloderm for dorsal nasal irregularities. Plast Reconstr Surg 2001;107:559-60.

7. Gourney M. The ear as a donor site: Anatomic and technical guidelines. In: Tanzer RD, Edgerton MD, editors. Symposium on Reconstruction of the Auricle. St. Louis: Mosby; 1974. p. 106.

8. Abdel-Haleem AK, Nouby R, Taghian M. The use of the rib grafts in head and neck reconstruction. Egypt J Ear Nose Throat Allied Sci 2011;12:89-98.

9. MacIntosch RB. Current spectrum of costochondral and dermal grafting. In: Bell WH, editor. Modern Practice in Orthognathic and Reconstructive Surgery. Vol. 2. Philadelphia: WB Saunders;1992. p. 872-949.

10. Donkor P, Bankas DO, Boakye G, Ansah S, Acheampong A. The use of free autogenous rib grafts in maxillofacial reconstruction. Ghana Med J 2006;40:127-31.

11. Ahmed J, Chuckwulobelu R, Sebire NJ, Hartely RE, Dunaway DJ. Hemimandibulectomy and autologous costochondral rib graft reconstruction for a case of melanotic neuroectodemal tumour of infancy arising within the mandible. Int $\mathrm{J}$ Pediatr Otolarhinolaryngol Extra 2007;2:189-93. 